\title{
Prevalence of Certain Chronic Complications of Diabetes among Type 2 Diabetic Patients in Rural Population of Kancheepuram District, Tamil Nadu- A Cross Sectional Study
}

\author{
Karthikeyan Maniarasu' ${ }^{1}$, Logaraj Muthunarayanan²
}

\section{Karthikeyan Mania- rasu ${ }^{1}$, Logaraj Muthuna- rayanan $^{2}$}

\section{'Department of Community Medicine SRM Medical college hospitals \& Research Centre, Kattankulathur - 603203,India. \\ 2Professor of Community Medicine, SRM Medical College Hospital and Research Center, Kattankulathur - 603203, India. *'These authors contributed equally to this work."}

\section{Correspondence \\ Dr. M.Karthikeyan}

Department of Community Medicine,

SRM Medical college Hospital \&

Research centre, Kattankulathur -

603203

Cell: 9840730865

E-mail address: dr.carthick@gmail.com

\section{History}

- Submission Date: 11-04-2016

- Revision Date : 15-12-2016

- Accepted Date: 17-01-2017

DOI : 10.5530ijmedph.2017.1.7

Article Available online

http://www.ijmedph.org/v7/i1

\section{Copyright}

(C) 2017 Phcog.Net. This is an openaccess article distributed under the terms of the Creative Commons Attribution 4.0 International license.

\begin{abstract}
Background: Nearly $50 \%$ of diabetics in India are undiagnosed and that the newly diagnosed diabetes patients are often found to have signs of complications. Objectives: To estimate the prevalence of diabetic complications, other than retinopathy and peripheral vascular disease, among known diabetic patients treated at healthcare centers in Kancheepuram district of Tamil Nadu; and to analyze the associations between chronic complications and patient's demographics, T2DM characteristics. Methodology: A cross sectional study was carried out in sixteen out of fifty six health care centers in Kancheepuram district in Tamil Nadu by cluster sampling method using the semi-structured questionnaire, with medical record, physical examination and biochemical investigation to identify chronic kidney disease and co-morbid conditions of type 2 diabetes. A Disability Neuropathy Score (DNS) of more than zero and negative monofilament/vibration tests were used to classify patients as having signs of peripheral neuropathy. Results: Prevalence of Ischemic heart disease and stroke were $7.8 \%$ and $0.5 \%$ respectively. Prevalence of stage I kidney disease based on the KDOQl guidelines using the estimated GFR and urine PCR values was $30.7 \%$, while chronic kidney disease (i.e., stage II or III or PCR $>0.2$ ) was seen in $10.4 \%$ patients. Based on the DNS scoring chart 59\% of them had peripheral neuropathy while $19 \%$ of them had signs of peripheral neuropathy. Participants with at least one chronic complication of diabetes (excluding retinopathy) were 32.8 percent. Prevalence of hypertension was $61.4 \%$. and Hyperlipidemia was $85.9 \%$, while high LDL, TGL was seen with $60.9 \%$ and $64.6 \%$ respectively, low HDL among $83.9 \%$ of patient. Conclusion: The high prevalence of undiagnosed microvascular complications in known diabetics treated at primary care emphasis a strong need for routine screening for complications of diabetes and to create awareness on its early detection and prevention of progression.
\end{abstract}

Key words: Prevalence, Type 2 diabetes complications, peripheral neuropathy, chronic kidney disease, primary health centre.

\section{INTRODUCTION}

The type 2 diabetes (T2DM) being the most common type of diabetes has a relatively asymptomatic phase between the actual onset of the condition and its clinical diagnosis which is estimated to 4-7 years. ${ }^{1,2}$ The diabetics in low and middle income countries who contribute to $70 \%$ of diabetics have limited access to diabetic care. ${ }^{3}$ As a progressive disease diabetic patients are frequently diagnosed with chronic complications including cardiovascular disease, nephropathy, coronary heart disease, retinopathy, and neuropathy. The prevalence of these complications of diabetes is generally expected to be proportional with the duration of diabetes and degree of glycemic control. ${ }^{4}$ This is of concern as $50 \%$ of diabetics in India are undiagnosed ${ }^{5}$ and that the newly diagnosed diabetes patients are often found to have signs of these complications. Late or undiagnosed cases become victims of diabetic complications early in their life which are directly responsible for poor quality of life, economical catastrophe, premature death and incur heavy burden to the health care system. ${ }^{3}$ Diabetes mellitus basically produces changes in the blood vessels and therefore affect almost every part of the body. Diabetic nephropathy has become a world epidemic accounting for one third of all cases of End Stage Renal Disease worldwide. ${ }^{5}$ More than half of non-traumatic amputations are due to diabetic complication. About 11\% of total health expenditure for adults in the world is spent on diabetics. ${ }^{6}$ A significant economical burden is imposed on both the state and the individual for treatment of diabetic complications.

India has a prevalence of $8.7 \%$, higher than the world prevalence. Every seventh type 2 diabetes patient in the world is an Indian. ${ }^{7}$ A quarter of all diabetic deaths happen in India. Study by Mohan et al (CUPS study) has shown that mortality rates are twofold higher in diabetic people when compared to non- 
diabetics in India ${ }^{8}$ and two studies done in India showed that diabetes related deaths in India is dominated by infections and renal failure unlike cardiovascular or cerebrovascular causes which dominate the developed countries.9, 10 The type 2 diabetes burden in India is escalating, more prevalent in the southern region of the country primarily due to changes in socioeconomic conditions, dietary habits and reduced physical activity. ${ }^{11}$ South India is a high carbohydrate consuming region with rice being their predominant food intake. Studies by Mohan et al in 1998 showed that complications were quite high even at the time of diagnosis of diabetes probably due to its insidious onset and long duration of asymptomatic disease before symptoms develop. In most cases the first presentation of diabetes would be associated with its complication.

Information on the prevalence of T2DM related complications is helpful in aiding adjustments in policies and practices in diabetic care management to gain better control of T2DM and this study was aimed at describing the prevalence of diabetic complications, other than diabetic retinopathy and peripheral vascular disease, among known diabetic patients treated at healthcare centers in Kancheepuram district of Tamil $\mathrm{Nadu}$; and to analyze the associations between chronic complications and patient's demographics, T2DM characteristics.

\section{METHODOLOGY}

A cross sectional study was carried out in sixteen out of the total fifty six health care centers in Kancheepuram district in Tamil Nadu using cluster sampling method, considering each primary care centers as a cluster. Twelve consecutive outpatients in each of the hospital who were willing to participate in the study and fulfilled the inclusion criteria of being a known case of diabetic and treated at the hospital were included in the study making into the required sample size of 192 estimated with assumption of proportion of $27 \%$ \{Prevalence and risk factors for diabetic neuropathy in an urban south Indian population: the Chennai Urban Rural Epidemiology Study (CURES-55) Pradeep et al, 2008\}, CI-95\% and an absolute precision of \pm 7 percent and $20 \%$ non response rate. The study was done between February-April 2013. The participants were given detailed information about the study. The subjects were interviewed using the semi-structured questionnaire to capture information about demographics, personal and medical history. Medical records and prescription review were done to know if they had cardiovascular and cerebrovascular complications. We also took their anthropometric measurements and blood pressure. Blood samples $(5 \mathrm{ml})$ were collected from all the subjects for testing blood sugar levels, serum creatinine and lipid levels. Also spot urine was collected to test for urine sugar and protein. Those samples which tested positive for urine protein were transported to laboratory for further investigation. Testing for retinopathy was not included in the study.

The complications of Ischemic Heart Disease and Stroke were identified from Patient's past medical history and review of medical records. To identify patients with Chronic Kidney Disease measurements of both serum creatinine and protein positive urine samples were taken and used the serum creatinine levels to calculate eGFR using the MDRD (Modification of Diet in Renal Disease) formula ${ }^{12}$. Urine levels of protein and creatinine were also used to calculate Protein-Creatinine Ratio (PCR). The KDOQI guidelines were used for staging of renal disease and chronic kidney disease. ${ }^{13}$

To identify Peripheral Neuropathy, patient were interviewed in person about their symptoms such as feeling of pins and needles, sharp pain, aching pain, numbness in their legs/feet and examined for vibratory sensation perception using $128 \mathrm{-Hz}$ tuning fork placed on bony prominence at the dorsum of great toe and both malleoli. Superficial sensation was tested using the 10 -g Semmes-Weinstein monofilament over six areas of feet for all the study participants. A Disability Neuropathy Score (DNS) of more than zero and negative monofilament/vibration tests were used to classify patients as having signs of peripheral neuropathy.

Patients with TGL levels $>150 \mathrm{mg} / \mathrm{dl}$ or calculated LDL levels $>100 \mathrm{mg} / \mathrm{dl}$ or $\mathrm{HDL}<40 \mathrm{mg} / \mathrm{dl}$ for males and $<50 \mathrm{mg} / \mathrm{dl}$ for females were classified as having dyslipidemia.

Patients with known history of hypertension or with a systolic blood pressure of $\geq 140 \mathrm{~mm}$ of $\mathrm{Hg}$ or with a diastolic blood pressure of $\geq 90 \mathrm{~mm}$ of $\mathrm{Hg}$, measured using a standard sphygmomanometer on the right arm in sitting position after making sure the patient had at least rested 10- 15 minutes on reaching the hospital, were considered as those with hypertension. All individuals included in the study provided written informed consent. The study was approved by the Institutional Ethics Committee.

Data were analyzed using Microsoft excel and Epi info 3.5.3. Descriptive data were presented as mean and proportion. A univariate analysis was used to derive at unadjusted odds ratios (OR) to measure the strength of association with 95\% confidence intervals and multivariate analysis to derive at the adjusted odds ratio with $95 \%$ confidence interval. Chi-square test was used to lend statistical support to prove associations between categorical variables. Mann-Whitney test and modified t test were used to the relationship between continuous variable.

\section{RESULTS}

\section{Socio-demographic profile of the study participants}

A total of 192 patients were included in the study based on the inclusion criteria, of which $77.1 \%(148 / 192)$ were women and $22.9 \%(44 / 192)$ were men. About $81 \%(183 / 192)$ were above the age of 40 years. While $42.7 \%(82 / 192)$ of them were uneducated, the retired/jobless and homemakers combined to make up $76 \%(146 / 192)$ of the study population. Although tobacco usage and alcohol consumption were $21.8 \%(42 / 192)$ and $12.5 \%$ (24/192) respectively, there was a higher percentage (around $63 \%$ ) of them who persisted with their habits even after being diagnosed with diabetes. A positive family history of diabetes was seen with $35.4 \%$ (68/192) of the study population. About $85 \%$ ( 164/192) said it took not more than 30 minutes to reach their health care center from home and $45 \%$ came by walk. Nearly $44.8 \%$ ( $86 / 192)$ of the study population had a body mass index (BMI) of over $25 \mathrm{~kg} / \mathrm{m}^{2}$ thus getting classified as obese. About $54.7 \%(105 / 192)$ of them said they adhered to diabetic diet and $34.9 \%(67 / 192)$ had said they have increased their physical activity after being diagnosed with diabetes.

\section{Prevalence of chronic complications of diabetes and co-morbidities}

Table 1 depicts the prevalence of chronic complications of diabetes and co-morbidities. The prevalence of Ischemic heart disease and stroke were $7.8 \%(95 \% \mathrm{CI}=4.02-11.60)$ and $0.5 \%(0.17-3.33)$ respectively. The prevalence of kidney disease based on the KDOQI guidelines using the estimated GFR and urine PCR values, 30.7\% ( 95\% CI=23.52-37.92) of the study population had stage I disease while chronic kidney disease (i.e., stage II or III or PCR $>0.2$ ) was seen in $10.4 \%$ patients. Based on the DNS scoring chart 59\% ( $95 \% \mathrm{CI}=51.62-67.13$ ) of the study population interviewed fell into the category of having symptoms of peripheral neuropathy while the monofilament/vibration test done on each of the study participants gave prevalence of $19 \%(95 \% \mathrm{CI}=10.89-26.61)$ for peripheral neuropathy. The total number of study participants with at least one chronic complication of diabetes (excluding retinopathy) was 32.8 percent. The prevalence of co-morbid hypertension among the diabetic study population was $61.4 \%$ (95\% CI= 53.21-69.70) out of which $13 \%(95 \% \mathrm{CI}=7.18$ - 18.86) were newly diagnosed during the study. Hyperlipidemia was prevalent among $85.9 \%$ (165/192) of the study 
Table1: Prevalence of chronic complications and co-morbidities among type 2 diabetes patients ( $\mathbf{n}=192$ )

\begin{tabular}{|c|c|c|c|}
\hline Complications/Co-morbidities & No. & Prevalence (\%) & $95 \% \mathrm{Cl}$ \\
\hline Ischemic heart disease & 15 & $(7.8)$ & $4.02-11.60$ \\
\hline Stroke & 2 & $(0.5)$ & $0.17-3.33$ \\
\hline \multicolumn{4}{|c|}{ Kidney disease } \\
\hline Stage I (eGFR 60-89) & 59 & $(30.7)$ & $23.52-37.92$ \\
\hline Stage II (eGFR 30-59) & 10 & $(5.2)$ & $2.45-7.95$ \\
\hline Stage III (eGFR 15-29) & 1 & $(0.5)$ & $0.02-2.49$ \\
\hline PCR $>0.2$ & 11 & $(5.7)$ & $2.60-8.85$ \\
\hline eGFR $<60$ or $\mathrm{PCR}>0.2$ & 20 & $(10.4)$ & $4.68-16.14$ \\
\hline \multicolumn{4}{|c|}{ Peripheral neuropathy } \\
\hline Positive Monofilament/ Vibration test & 36 & $(18.8)$ & $10.89-26.61$ \\
\hline DNS score $>0$ (only) & 114 & $(59.4)$ & $51.62-67.13$ \\
\hline \multicolumn{4}{|c|}{ Hypertension } \\
\hline Known hypertensive's & 93 & $(48.4)$ & $40.13-56.74$ \\
\hline Newly detected hypertensive's & 25 & $(13.0)$ & $7.18-18.86$ \\
\hline Total hypertensive's & 118 & $(61.5)$ & $53.21-69.70$ \\
\hline \multicolumn{4}{|c|}{ Dyslipidemia } \\
\hline High Total Cholesterol $(\geq 200 \mathrm{mg} / \mathrm{dl})$ & 87 & $(45.3)$ & $36.73-53.88$ \\
\hline High TGL $(\geq 150 \mathrm{mg} / \mathrm{dl})$ & 117 & $(60.9)$ & $53.55-68.31$ \\
\hline High LDL ( $\geq 100 \mathrm{mg} / \mathrm{dl})$ & 124 & $(64.6)$ & $61.27-76.50$ \\
\hline High Non-HDL ( $\geq 130$ mg/dl) & 138 & $(71.9)$ & $62.86-80.88$ \\
\hline Low $\mathrm{HDL} \leq 40$ for males and $\leq 50$ for females & 161 & $(83.9)$ & $76.16-91.54$ \\
\hline Any one complication\# & 63 & $(32.8)$ & $26.20-39.90$ \\
\hline
\end{tabular}

\#- IHD or stroke or CKD or peripheral neuropathy

population. While high LDL, TGL was seen with $60.9 \%$ and $64.6 \%$ respectively, low HDL was seen among $83.9 \%$ of these diabetics.

Figure 1 depicts newly detected complications and co-morbidities among diabetes patients. A large proportion of diabetic complications such as chronic kidney disease 19 out of 20 cases of chronic kidney diseases were newly detected cases (95\%), all 36 peripheral neuropathy cases detected were new cases (100\%) and $96 \%$ of hyperlipidemia cases detected were new cases while a large proportion of the total hypertensive's were known/ old cases.

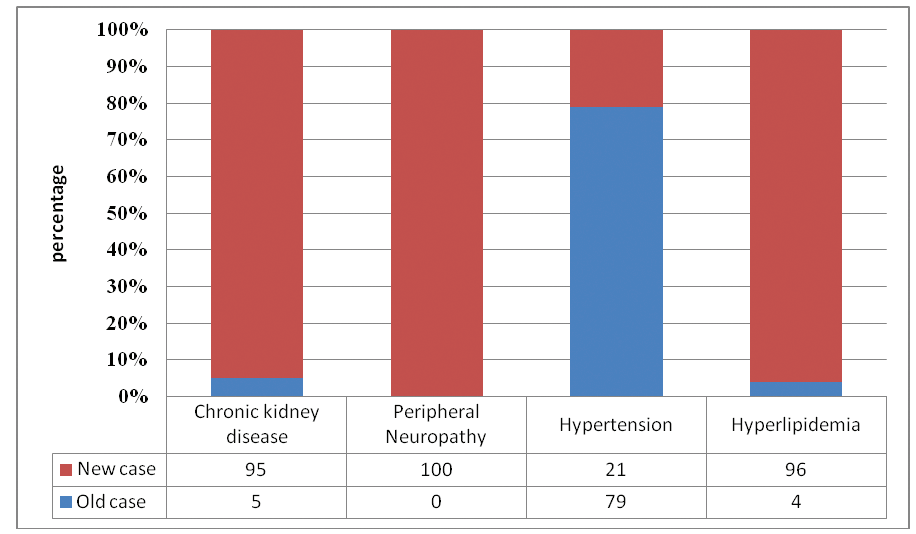

Figure 1: The proportion of newly detected diabetic complications and co-morbidities among all T2DM patients treated at health care centers

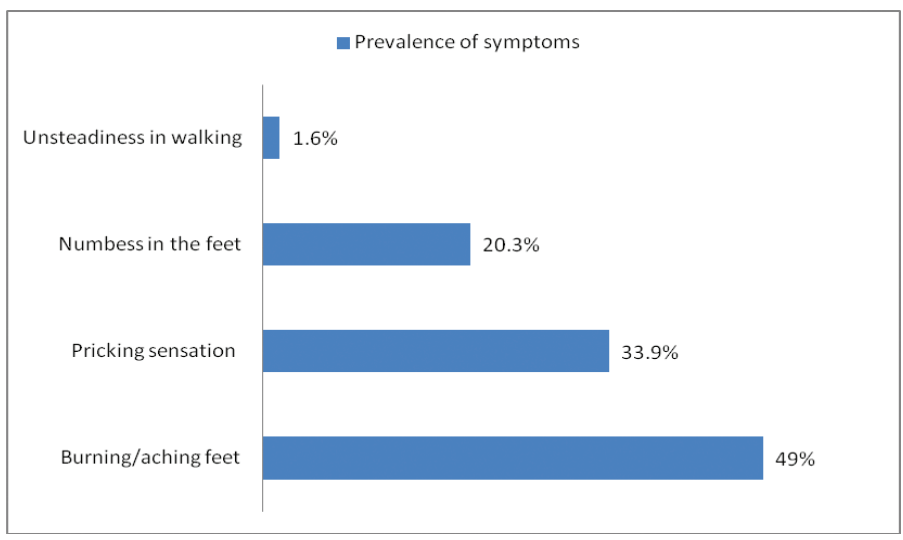

Figure 2: Prevalence of symptoms of peripheral neuropathy among T2DM patients treated at health care centers

Table 2 shows the mean parameters of diabetic patients with and without peripheral neuropathy and chronic kidney disease. While increasing age (60 \pm 10.59$)$ was significantly associated with peripheral neuropathy, high total cholesterol $(220 \pm 69.78)$ high TGL (248) and Non-HDL levels $(182.65 \pm 65)$ were significantly associated with chronic kidney disease. Patients with higher duration of diabetes and those who had longer duration of travel to the health care center had significantly higher association with chronic kidney disease. The mean duration of diabetes was seen to be higher both in those who had peripheral neuropathy and chronic kidney disease when compared to those who did not, although not statistically significant. 


\begin{tabular}{|c|c|c|c|c|}
\hline \multirow[t]{2}{*}{ Variables } & \multicolumn{2}{|c|}{ Peripheral neuropathy } & \multicolumn{2}{|c|}{ Chronic kidney disease } \\
\hline & Present $(n=36)$ & Absent $(n=156)$ & Present $(n=20)$ & Absent $(n=172)$ \\
\hline Age, yrs & $60.13 \pm 10.59^{s}$ & $54.98 \pm 10.15$ & $56.40 \pm 10.35$ & $55.9 \pm 10.44$ \\
\hline $\mathrm{BMI}, \mathrm{kg} / \mathrm{m}^{2}$ & $24.00 \pm 4.52^{\$}$ & $25.04 \pm 4.02$ & $24.13 \pm 3.37$ & $24.93 \pm 4.20$ \\
\hline SBP, mm Hg & $133.22 \pm 20.10$ & $128.76 \pm 18.51$ & $130.5 \pm 20.89$ & $129.5 \pm 18.65$ \\
\hline DBP, mm Hg & $80.72 \pm 10.55$ & $79.20 \pm 11.12$ & $79.4 \pm 11.57$ & $79.5 \pm 10.97$ \\
\hline DM duration, months & $48^{*}$ & 36 & $48^{*, \$}$ & 36 \\
\hline $\mathrm{TC}, \mathrm{mm} / \mathrm{dl}$ & $198.97 \pm 56.56$ & $195.09 \pm 45.49$ & $220 \pm 69.78^{\#, s}$ & $193 \pm 43.76$ \\
\hline $\mathrm{LDL}, \mathrm{mm} / \mathrm{dl}$ & $109.93 \pm 28.63$ & $116.72 \pm 36.96$ & $121.93 \pm 63.55^{\#}$ & $114.89 \pm 32.17$ \\
\hline TGL, mm/dl & $242.75 \pm 232.74^{*}$ & $203.58 \pm 110.93$ & $248^{\varsigma}$ & 179 \\
\hline Non-HDL, mm/dl & $158.69 \pm 54.96$ & $156.63 \pm 42.93$ & $182.65 \pm 65.05^{\#, \$}$ & $154.04 \pm 41.64$ \\
\hline Travel time to PHC, minutes & $26.94 \pm 22.1$ & $24.13 \pm 16.79$ & $32.5 \pm 27.26^{\#, S}$ & $23.75 \pm 16.33$ \\
\hline
\end{tabular}

Table 3: Association between presence of at least one complication and risk factors for complication among the T2DM patients treated at health care centers

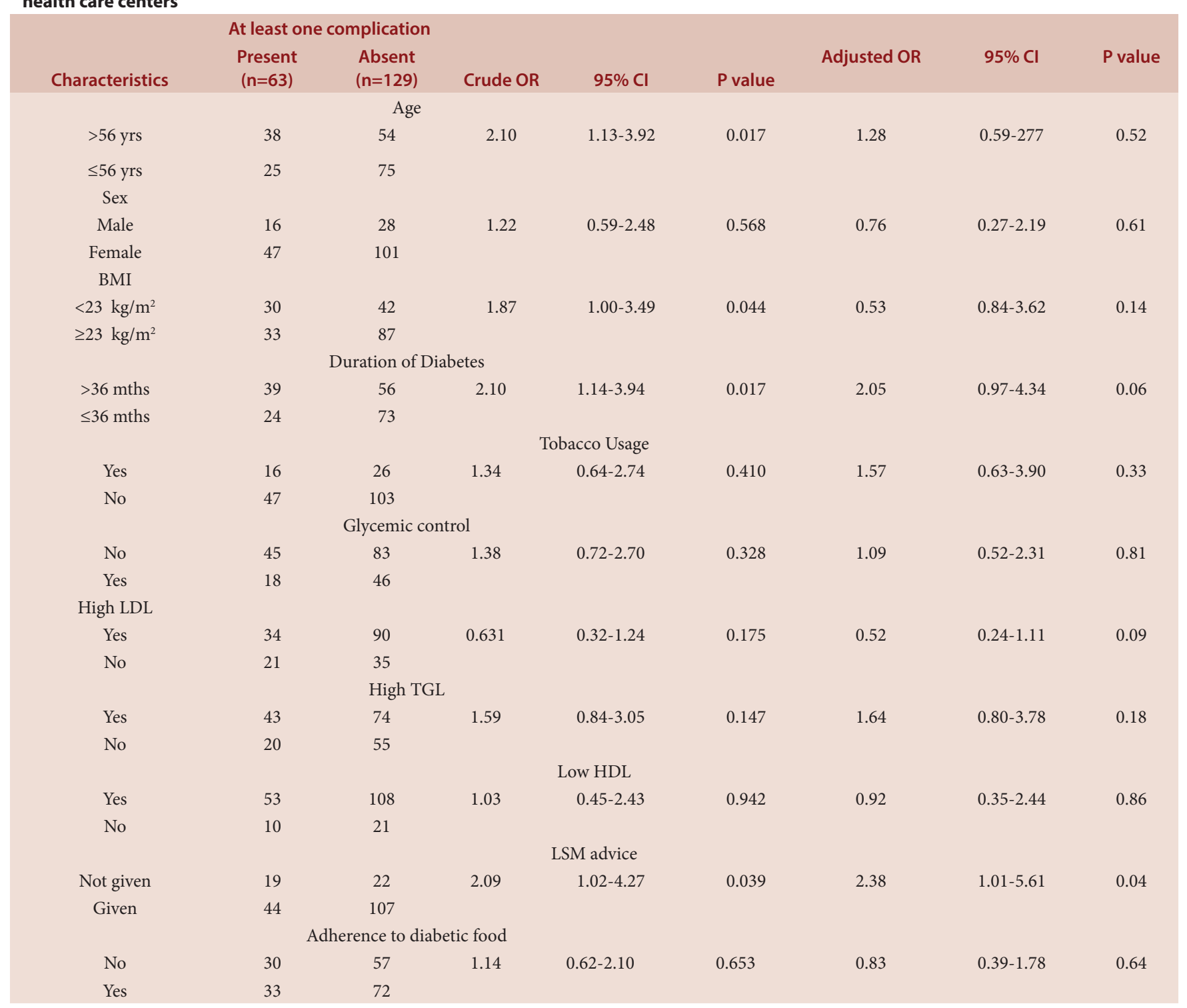


Table 3 shows the association between presence of atleast one complication and risk factors for diabetic complications. The univariate analysis with risk factors for diabetic complications showed that elderly (over 56 years) had two times the odds of getting atleast one complication of diabetes, similarly those with increased duration of diabetes (more than 36 months) had two times the odds and those who did not get any advice on life style modification also had twice the odds of getting atleast one complication of diabetes. Strangely, those with lower BMI had significantly higher chances of getting atleast one complication of diabetes. But on adjusted odds ratio, only those who did not receive any advice on life style modification were found to be significantly associated to have atleast one complication of diabetes.

\section{DISCUSSION}

The chronic complications have a significant role in the T2DM related morbidity and mortality, and the burden it impinges on the health care resources. ${ }^{3}$ Hence it is important to understand the epidemiology of T2DM complications and its co-morbidities. This paper looks into the prevalence of chronic complications of diabetes (excluding retinopathy) among type 2 diabetic patients treated at health care centers in Kancheepuram district of Tamil Nadu. To our knowledge, this could be the first report made for estimating the prevalence of complications of diabetic in health care centers in rural areas of Tamil Nadu.

In this study, the observation that nearly $9 \%$ of the participants were below 40 years of age has stood by the fact that Indians have a higher chance of getting diabetes at an earlier age when compared to other population in the world. ${ }^{14}$

Prevalence of peripheral neuropathy diagnosed using the monofilament and vibration tests of $18.75 \%$, consistent to the study done by Ashok among patients attending a diabetic clinic in south India using biothesiometry ${ }^{15}$ while it was lower than in Pakistan which gave a higher prevalence of $39.6 \%{ }^{16}$ The mean age of those patients with neuropathy was older (60.13 years compared to patients without neuropathy (54.98years) it was statistically significant $(\mathrm{p}<0.05)$. The DNS score chart that scores the patient based on his/her symptom of peripheral neuropathy gave a prevalence of $59.3 \%$ among the study population which was higher than a similar study done in2011 at Benghazi, Libya which showed a prevalence of $47.1 \%$ for peripheral neuropathy, ${ }^{17}$ Detecting neuropathy earlier will prevent varying number of foot complications and hospitalization..$^{18}$ In our current study we observed that none of the patients who were screened and diagnosed with neuropathy had previously been diagnosed. Studies by Litzelman and Rith-Najarian reported that in intervention groups there was significant reduction of serious foot ulceration. ${ }^{19,20}$

The prevalence of chronic kidney disease $\left(\mathrm{eGFR}<60 \mathrm{ml} / \mathrm{mt}\right.$ per $1.73 \mathrm{~m}^{2}$ and/or urine PCR $>0.2)^{[21,22]}$ was $10.41 \%$ and that of early stage renal disease (Stage I) ${ }^{23}$ was $30.72 \%$. Asian studies done among general population had shown prevalence of CKD to be 3-5\% in southern China, $13 \%$ in southern Taiwan, 9.2\% in Japan and 5.2\% in Indonesia. ${ }^{24}$ The community in Delhi on the prevalence of low eGFR was $4.2 \%{ }^{25}$ Study done by Weiping Jia among diabetic patients in China revealed a prevalence of $29.6 \%{ }^{26}$ and a global prevalence of $22 \%{ }^{27}$ for CKD. A similar study done by Chadban et al in Australia ${ }^{28}$ had a prevalence of $11.2 \%$ for eGFR $<60 \mathrm{ml} / \mathrm{mt}$ per $1.73 \mathrm{~m}^{2}$. Most of the studies on nephropathy had been done using microalbumuria and macroalbuminuria measurements or by calculating the urine albumin creatinine ratio. With diabetic nephropathy being the leading cause of end-stage renal disease worldwide and microalbuminuria being considered an important predictor for cardiovascular disease, ${ }^{29}$ it is vital therefore to catch them early and treat to prevent any progression of the condition. The prevalence of ischemic heart disease of
$7.8 \%$ was less compared to $14.9 \%$ stated by a study done in Libya, ${ }^{17} 22 \%$ in a study done in Pakistan ${ }^{14}$ and $32.3 \%$ as in a study done at Goa. ${ }^{28}$ The CUPS study done in Chennai revealed a prevalence of $21.4 \%$ for coronary artery disease. ${ }^{29}$ The prevalence of stroke was also seen high in the Pakistan study ${ }^{16}$ when compared to the current study which has given a prevalence of $1.02 \%$. Hypoglycemia is not just a problem for that day of its occurrence, the counter regulatory response it initiates has shown to increase cardiac risk, cerebral ischemia, stroke. ${ }^{30}$ Recent studies by Khunti et al and Hanfeld et al in diabetic care have identified hypoglycemia to have a strong association with macrovascular events, unfavorable clinical outcomes and mortality. Prevalence of at least one diabetic complication is $32.8 \%$ in our study. The age and duration of diabetes was significantly higher $(p<0.05)$ among those with at least one complication. This study has observed that people who did not get LSM advice had statistically significant association of developing at least one of the chronic complications of diabetes.

\section{CONCLUSION}

In summary, our study has observed that the prevalence of diabetic neuropathy among patients treated at health care centers $59 \%$ based on DNS scoring chart. The prevalence of diabetic nephropathy was 30.7 percent. More than $90 \%$ of both these microvascular complications in our study population were newly diagnosed. It is thus quite evident that there is a strong need for routine screening mechanism at the primary care level, not only for early detection but also for prevention of their progression. Also the fact that lack of LSM advice is a significant risk factor advocates the need for promoting more awareness on complications of diabetes and ways to prevent them.

\section{Limitations}

Taking into consideration of the cost constraints certain diabetic complications such as peripheral vascular disease and diabetic retinopathy were not covered in this study.

\section{ACKNOWLEDGEMENT}

Nil

\section{CONFLICT OF INTEREST}

Nil

\section{ABBREVIATIONS USED}

KDOQI: Kidney Disease Outcomes Quality Initiative; DNS: Diabetic Neuropathy Symptom Score; LDL: Low Density Lipids; HDL: High Density Lipids; TGL: Triglycerides; EGFR: Estimated Glomerular Filtration rate.

\section{REFERENCES}

1. Heydari I, Radi V, Razmjou S, Amiri A. Chronic complications of diabetes mellitus in newly diagnosed patients. International Journal of Diabetes Mellitus. 2010;2(1):61-3. https://doi.org/10.1016/j.ijdm.2009.08.001.

2. Harris MI, Klein R, Welborn TA, Knuiman MW. Onset of NIDDM occurs at least 4-7 yr before clinical diagnosis. Diabetes Care. 1992;15(7):815-9. https://doi. org/10.2337/diacare.15.7.815; PMid:1516497

3. Zhaolan L, Chaowei F, Weibing W, Biao X. Prevalence of chronic complications of type 2 diabetes mellitus in outpatients-a cross-sectional hospital based survey in urban China. Health and Quality of Life Outcomes. 2010;8(1):62. https:// doi.org/10.1186/1477-7525-8-62 ; PMid:20579389 PMCid:PMC2906445.

4. Rhee SY, Chon S, Kwon MK, Park IB, Ahn KJ, Kim IJ, et al. Prevalence of chronic complications in Korean patients with type 2 diabetes mellitus based on the Korean National Diabetes Program. Diabetes \& metabolism journal. 2011;35(5):504-12. https://doi.org/10.4093/dmj.2011.35.5.504; PMid:22111042 PMCid:PMC3221026.

5. Rossing PD. Diabetic nephropathy: worldwide epidemic and effects of current treatment on natural history. Current diabetes reports. 2006;6(6):479-83 
https://doi.org/10.1007/s11892-006-0083-y; PMid:17118233.

6. Federation ID. The Global Burden. 6th edition 2012. Accessed on 29.12.2016 https://www.idf.org/sites/default/files/EN_6E_Atlas_Full_0.pdf

7. Federation ID. IDF Diabetes Atlas. 5th edition 2012. Accessed on 29.1.2016 http://www.indiaenvironmentportal.org.in/files/file/diabetes\%20atlas\%202012.pdf

8. Mohan V, Shanthirani C, Deepa M, Deepa R, Unnikrishnan R, Datta M. Mortality rates due to diabetes in a selected urban south Indian population-the Chennai Urban Population Study [CUPS-16]. Journal of the Association of Physicians of India. 2006;54:113-7. PMid:16715613.

9. Zargar A, Wani A, Masoodi S, Bashir M, Laway B, Gupta V, et al. Causes of mortality in diabetes mellitus: data from a tertiary teaching hospital in India. Postgraduate medical journal. 2009;85(1003):227-32. https://doi.org/10.1136/ pgmi.2008.067975; PMid:19520872.

10. Bhansali A, Chattopadhyay A, Dash RJ. Mortality in diabetes: a retrospective analysis from a tertiary care hospital in North India. Diabetes research and clinical practice. 2003;60(2):119-24. https://doi.org/10.1016/S0168-8227(03)00013-5.

11. Gupta R, Misra A. Review: Type 2 diabetes in India: regional disparities. The British Journal of Diabetes \& Vascular Disease. 2007;7(1):12-6. https://doi.org/1 $0.1177 / 14746514070070010301$.

12. National Kidney Foundation. KDOQI Clinical Practice Guideline for Diabetes and CKD: 2012 update. Am J Kidney Dis. 2012;60(5):850-86 https://doi.org/10.1053/j. ajkd.2012.07.005; PMid:23067652.

13. Kramer H, Mark E. Molitch. Screening for kidney disease in adults with diabetes. Diabetes Care. 2005;28(7):1813-6. https://doi.org/10.2337/diacare.28.7.1813 ; PMid: 15983346

14. Yajnik C. Early life origins of insulin resistance and type 2 diabetes in India and other Asian countries. The Journal of nutrition. 2004;134(1):205-10. PMid: 14704320

15. Ashok S, Ramu M, Deepa R, Mohan V. Prevalence of neuropathy in type 2 diabetic patients attending a diabetes centre in South India. JAPI. 2002;50:546-50. PMid:12164406

16. Shera A, Jawad F, Maqsood A, Jamal S, Azfar M, Ahmed U. Prevalence of chronic complications and associated factors in type 2 diabetes. J Pak Med Assoc. 2004;54(2):54-9. PMid:15134204.

17. Roaeid R, Kadiki O. Prevalence of long-term complications among Type 2 diabetic patients in Benghazi, Libya. Journal of Diabetology. 2011;3(5):1-8

18. Leung G, Lam K. Diabetic complications and their implications on health care in Asia. Hong Kong Medical Journal. 2000;6(1):61-8. PMid:10793404.

19. Litzelman DK, Slemenda CW, Langefeld CD, Hays LM, Welch MA, Bild DE, et al. Reduction of lower extremity clinical abnormalities in patients with noninsulin-dependent diabetes mellitusA randomized, controlled trial. Annals of Internal Medicine. 1993;119(1):36-41. https://doi.org/10.7326/0003-4819-119-1199307010-00006 ; PMid:8498761.
20. Rith-Najarian SJ, Stolusky T, Gohdes DM. Identifying diabetic patients at high risk for lower-extremity amputation in a primary health care setting: a prospective evaluation of simple screening criteria. Diabetes Care. 1992;15(10):1386-9. https://doi.org/10.2337/diacare.15.10.1386; PMid:1425105.

21. 1Stevens LA, Coresh J, Greene T, Levey AS. Assessing kidney functionmeasured and estimated glomerular filtration rate. New England Journal of Medicine. 2006;354(23):2473-83. https://doi.org/10.1056/NEJMra054415; PMid:16760447.

22. Notebook FP. Urine Protein to Creatinine Ratio. 2010. Accessed on 29.1.2016 http://www.fpnotebook.com/uro/Lab/UrnPrtnTCrtnRt.htm.

23. Foundation NK. KDOQI guidelines. 2013. Accessed on 29.1.2016 https://www. kidney.org/professionals/guidelines.

24. Tsukamoto Y, Wang H, Becker G, Chen H-C, Han D-S, Harris D, et al. Report of the Asian Forum of Chronic Kidney Disease Initiative (AFCKDI) 2007. "Current status and perspective of CKD in Asia": diversity and specificity among Asian countries. Clin Exp Nephrol. 2009;13(3):249-56. https://doi.org/10.1007/s10157009-0156-8 ; PMid:19288169.

25. Singh NP, Ingle GK, Saini VK, Jami A, Beniwal P, Lal M, et al. Prevalence of low glomerular filtration rate, proteinuria and associated risk factors in North India using Cockcroft-Gault and Modification of Diet in Renal Disease equation: an observational, cross-sectional study. BMC nephrology. 2009;10(1): 4. https:// doi.org/10.1186/1471-2369-10-4 ; PMid:19220921 PMCid:PMC2663556.

26. Jia W, Gao X, Pang C, Hou X, Bao Y, Liu W, et al. Prevalence and risk factors of albuminuria and chronic kidney disease in Chinese population with type 2 diabetes and impaired glucose regulation: Shanghai diabetic complications study (SHDCS). Nephrology Dialysis Transplantation. 2009:24(12):3724-31. https://doi.org/10.1093/ndt/gfp349; PMid:19617258.

27. Parving $H$, Lewis J, Ravid M, Remuzzi G, Hunsicker L. Prevalence and risk factors for microalbuminuria in a referred cohort of type II diabetic patients: a global perspective. Kidney international. 2006;69(11):2057-63. https://doi. org/10.1038/sj.ki.5000377; PMid:16612330

28. Chadban SJ, Briganti EM, Kerr PG, Dunstan DW, Welborn TA, Zimmet PZ, et al. Prevalence of kidney damage in Australian adults: The AusDiab kidney study. Journal of the American Society of Nephrology. 2003;14(suppl 2):S131-8. https://doi.org/10.1097/01.ASN.0000070152.11927.4A ; PMid:12819318.

29. Mohan V, Deepa R, Rani SS, Premalatha G. Prevalence of coronary artery disease and its relationship to lipids in a selected population in South IndiaThe Chennai Urban Population Study (CUPS No. 5). Journal of the American College of Cardiology. 2001;38(3):682-7. https://doi.org/10.1016/S0735-1097(01)01415-2.

30. Desouza CV, Bolli GB, Fonseca V. Hypoglycemia, diabetes, and cardiovascular events. Diabetes Care. 2010;33(6):1389-94. https://doi.org/10.2337/dc09-2082; PMid:20508232 PMCid:PMC2875462.

Cite this article : Maniarasu K, Muthunarayanan L. Prevalence of certain chronic complications of diabetes among type 2 diabetic patients in rural population of Kancheepuram district, Tamil Nadu- A cross sectional study. Int J Med. Public Health. 2017; 7(1): 41-6. 